\title{
Enhancing heavy load wear resistance of AISI 4140 steel through the formation of a severely deformed compound-free nitrided surface layer
}

Wang, Bo; Liu, Bin; Zhang, Xiaodan; Gu, Jianfeng

Published in:

Surface and Coatings Technology

Link to article, DOI:

10.1016/j.surfcoat.2018.09.066

Publication date:

2018

Document Version

Peer reviewed version

Link back to DTU Orbit

Citation (APA):

Wang, B., Liu, B., Zhang, X., \& Gu, J. (2018). Enhancing heavy load wear resistance of AISI 4140 steel through the formation of a severely deformed compound-free nitrided surface layer. Surface and Coatings Technology, 356, 89-95. https://doi.org/10.1016/j.surfcoat.2018.09.066

\section{General rights}

Copyright and moral rights for the publications made accessible in the public portal are retained by the authors and/or other copyright owners and it is a condition of accessing publications that users recognise and abide by the legal requirements associated with these rights.

- Users may download and print one copy of any publication from the public portal for the purpose of private study or research.

- You may not further distribute the material or use it for any profit-making activity or commercial gain

- You may freely distribute the URL identifying the publication in the public portal 


\title{
Enhancing heavy load wear resistance of AISI 4140 steel through the formation of a severely deformed compound-free nitrided surface layer
}

\author{
Bo Wang ${ }^{\mathrm{a}, \mathrm{b}}$, Bin Liu $\mathrm{L}^{\mathrm{a}}$, Xiaodan Zhang ${ }^{\mathrm{b}}$, Jianfeng $\mathrm{Gu}^{\mathrm{a}}$ \\ ${ }^{a}$ Department of Materials Science and Engineering, Shanghai Jiao Tong University, \\ Shanghai 200240, China \\ ${ }^{b}$ Department of Mechanical Engineering, Technical University of Denmark, Kongens \\ Lyngby 2800, Denmark
}

The tribological application of gas nitriding on alloy gears used under high-speed and heavy-duty conditions has been limited owing to the intrinsic characteristics of the traditional gas-nitrided layers. Complex phenomena of wear failure are involved under such harsh conditions, therefore a tougher nitrided layer with excellent comprehensive performance is necessary to prevent them. To this aim a severely deformed compound-free nitrided layer with an outermost ultra-fine-crystalline layer and a subsurface deformed nitrogen diffusion zone was prepared on an AISI 4140 sample through the combined treatment of controlled gas nitriding and ultrasonic shot peening. The effect of the severely deformed compound-free nitrided layer on the hardness, toughness and wear properties was investigated. The enhanced wear resistance under heavy load after the combined treatment can be attributed to the good combination of surface hardness and toughness, as well as the significantly enhanced residual compressive stress. The two-step surface treatment provides an effective approach to enhancing the wear resistance of heavy-duty gears.

Keywords: Controlled gas nitriding; Ultrasonic shot peening; Compound-free nitrided layer; Wear resistance; Residual compressive stress

\section{Introduction}

Among the property requirements of alloy steel gears, wear resistance can be considered one of the most important reliability indexes. Apart from the direct material loss that leads to functional failure, surface wear causes the gear system to change its 
vibration and noise characteristics significantly as the gear mesh excitations are very sensitive to surface geometry [1]. During the meshing process of gears serving under high speed and heavy duty environments, vibration and the unexpected foreign/contamination particles often bring about transient local overloads along the contact profile, or in the contacting points of gear tooth surfaces [2-4]. The wear behavior under heavy loads would involve the abrasion, scuffing and contact fatigue, presenting more frequent and complex damage in surface and subsurface. However, little research has been focused on the wear behavior under such conditions. It is an important task to apply some technological process to enhance the wear property of materials under heavy loads. The evaluation of the wear behavior under heavy loads will provide the physical grounds for the wear failure analysis of heavy-duty gears.

It has been common practice for many years to improve gear wear resistance by some form of surface modification technologies [5-7]. Traditional gas nitriding (TGN), a typical thermochemical surface treatment, has been particularly effective in improving the hardness, wear resistance and fatigue properties of steels through the development of a unique gradient structure with the outermost compound layer (CL) and subsurface diffusion zone. The CL consisting of a heterogeneous mixture of $\varepsilon-\mathrm{Fe}_{2-3} \mathrm{~N}$ and $\gamma^{\prime}-\mathrm{Fe}_{4} \mathrm{~N}$ phases presents a relatively high hardness, which makes a positive contribution to wear resistance under light loads [7-9]. However, this layer suffers from high internal stress, which makes it friable and brittle, and will be crushed under conditions of impact and/or heavy loads [9-11]. Therefore, the CL has to be removed or completely suppressed, thus, the diffusion layer/compound-free nitrided layer becomes the load-bearing surface in service. Although brittle spalling could be avoided depending on the excellent toughness and bearing capacity of the diffusion layer, the relatively low surface hardness would weaken the maximum degree of enhancement in wear properties.

Grain refinement of the material surface by means of surface severe deformation can be regarded as one option that can not only significantly increase surface hardness and wear resistance without a loss of toughness, but also induce residual compressive stresses [12]. Recently, the surface mechanical attrition treatment (SMAT) as a 
pretreatment technique has been confirmed to be appropriate for reducing nitriding temperature and for shortening duration efficiently [12-14]. Due to the enhanced driving force for formation of compound layer, however, brittleness of the nitrided layer cannot be avoided by nitriding with pretreatment of surface severe deformation. Moreover, the residual compressive stresses induced by SMAT will be released by thermal exposure during the subsequent nitriding treatment $[15,16]$. In contrast, the synergistic effect of nitriding with following surface deformation can generate remarkable enhancement in surface and maximum compressive residual stress. Since the advantageous in terms of residual stress and its distribution characteristic, the combined treatment of nitriding and following surface deformation was adopted to improve the fatigue [16, 17] and rolling contact fatigue properties $[18,19]$. However, these investigations focus less on microstructure control during the combined treatment, especially with regard to the inhibition of formation of surface cracks during further severe deformation, which will strongly degrade the surface wear property. In consideration of the brittleness characteristic of the compound layer, a combined process of controlled pressurized gas nitriding and cold rolling was developed in our previous study. While the bearing capacity and wear resistance of steel 38CrMoAlA had been effectively improved, the cold rolling processes led to the weakening of the toughness and decreasing in the nitrided layer thickness [20]. Tong et al [15] performed ion sputtering on plasma nitrided 20CrMo samples to decompose the compound layer and subsequently subjected them to SMAT. The hardness, wear property of the plasma nitrided layer without compound layer was improved without sacrificing the toughness, especially remarkable augmentation was achieved for compressive residual stress. These research can provide the process and technical reference for preparing a tough gas nitrided layer which is expected to serve under heavy load conditions.

In the present study the surface microstructure against wear was controlled to be a severely deformed compound-free nitrided layer. Such a surface microstructure could be realized by controlled gas nitriding $(\mathrm{CGN})$ in order to reduce surface brittleness through the formation of the compound-free nitrided layer, followed by ultrasonic shot peening 
(USP). The present work aims to explore the wear behavior of typical gear-used AISI 4140 steel following the combined treatment of CGN and USP, and compare that with a traditional nitrided alloy.

\section{Experimental procedures}

\subsection{Sample preparation}

A CrMo low-alloy AISI 4140 steel plate of $70 \mathrm{~mm} \times 30 \mathrm{~mm} \times 10 \mathrm{~mm}$, with compositions of (mass \%) 0.41 C, 0.91 Cr, 0.18 Mo, 0.75 Mn, 0.18 Mo, 0.21 Si and bal. Fe was employed in this study. Prior to nitriding, the samples were oil-hardened from $850^{\circ} \mathrm{C}$ and tempered at $570^{\circ} \mathrm{C}$ to develop a uniform tempered martensite structure with a hardness of $350-370 \mathrm{HV}$. Prior to gas nitriding treatment, the samples were surface grinded and cleaned. It is advisable to reduce the value of the nitriding potential as time of process proceeds, in order not to exceed the border concentration of nitrogen in the diffusion zone, which would cause the formation of the $\varepsilon-\mathrm{Fe}_{2-3} \mathrm{~N}$ or $\gamma^{\prime}-\mathrm{Fe}_{4} \mathrm{~N}$ phases on the steel surface [21]. Gas nitriding treatments were performed at $530^{\circ} \mathrm{C}$ using flowing $\mathrm{NH}_{3}$ for $5 \sim 15 \mathrm{~h}$. In order to eliminate the thickness influence, two nitrided samples with the same thickness but different phase compositions were prepared. The effective case thicknesses of the samples nitrided at $530^{\circ} \mathrm{C}$ using nitriding potential of 2.80 for $11 \mathrm{~h}$ (TGN sample) and using a controlled low nitriding potential of 0.29 for $15 \mathrm{~h}$ (CGN sample) were approximately 239 and $258 \mu \mathrm{m}$, respectively. Surface phase composition and the effective case thickness of nitrided layers obtained within different experimental parameters are illustrated in Fig. 1. The post USP treatment was introduced in the compound-free nitrided layer to ensure that no brittle cracks would be formed. Bearing steel shots with hardness of 60 63 $\mathrm{HRC}$ and diameter of $0.8 \mathrm{~mm}$ were employed to conduct USP treatment at a vibrating frequency of $20 \mathrm{kHz}$ for $1 \mathrm{~h}$ in vacuum at room temperature. Because of the high frequency of the system, the entire surface of the nitride sample to be treated was peened with a very high number of impacts over a short period of time. Through the repeated impacts with multidirectional direction and high impact rates, severe plastic deformation and grain refinement are induced onto the 
sample surface. The shot peened TGN sample with a compound layer was used as a reference.

\subsection{Microstructural characterization}

The polished cross-section was etched by $3 \%$ nital for $8 \sim 10 \mathrm{~s}$. The cross-sectional observations of the treated samples were performed by using a ZEISS HAL 100 optical microscope $(\mathrm{OM})$ and a Tescan Lyra3 scanning electron microscope (SEM) with an operating voltage of $20 \mathrm{kV}$. The surface microstructure was characterized by means of a JEM-2010 transmission electron microscope (TEM) with an operating voltage of 200 $\mathrm{kV}$. TEM samples were prepared first by mechanical polishing, then by electropolishing, and were finally cleaned slightly by ion milling. Phase composition of the modified layers was investigated on a Rigaku Ultima IV X-ray diffractometer using the $\mathrm{Cu} \mathrm{K} \alpha$ radiation at $40 \mathrm{~mA}$ and $40 \mathrm{kV}$. Residual stress measurements were performed by a standard X-ray diffraction technique according to the $\sin 2 \psi$ method in the equipment X-350A X-ray stress analyzer (Handan Este Stress Technology Co., Ltd., Handan, China), using $\mathrm{Cr} \mathrm{K} \alpha$ radiation (elastic constant of $1 / 2 \mathrm{~s}_{2}=5.92 \times 10^{-6} \mathrm{MPa}^{-1}$; $\left.1 / 2 \mathrm{~s}_{1}=1.28 \times 10^{-6} \mathrm{MPa}^{-1}\right)$. The speed of the ladder scanning was $0.10 \mathrm{~s}^{-1}$ and the X-ray beam voltage and electricity were $20.0 \mathrm{kV}, 5.0 \mathrm{~mA}$, respectively. In depth measurements were performed step by step by removing a thin layer $(8 \sim 20 \mu \mathrm{m})$ using an electro-polishing device in order to obtain the residual stress profile.

\subsection{Hardness and wear test}

A Zwick hardness tester was used to measure the hardness of the modified layer with a load of $200 \mathrm{~g}$ for $10 \mathrm{~s}$ and to characterize the surface toughness using normal loads from 1 to $30 \mathrm{~kg}$. A pin-on-disc wear test device was employed to evaluate the unlubricated wear resistance of each treated surface layer by measuring the wear weight loss and examining the surface worn microstructure. The surface-modified sample (pin) is turned in an anticlockwise motion at $500 \mathrm{r} / \mathrm{min}$ in contact with the $\mathrm{GCr} 15$ steel disc (with a hardness of 60 63 HRC) at room temperature under normal loads of 49, 98, 147, $196,245,294,343,392 \mathrm{~N}$, respectively, with wear duration of $300 \mathrm{~s}$ and distance of 600 m. 


\section{Results and discussion}

\subsection{Microstructure}

After nitriding, the selected samples with and without compound layer were subjected to USP treatments under the same experimental conditions. It can be clearly seen that the surface of TGN sample was highly damaged and many micro-cracks were generated in and throughout the compound layer (Fig. 2a). Through the combined treatment of controlled gas nitriding and USP, a distinct region separated with sharp boundaries from the underlying layer was easily recognized on the top surface (Fig. 2b). This layer, representing a uniform and dense structure without cracks, is considered to be the fine grained layer [22]. This verifies the fact that the compound layer with high brittleness presents bad ability of deformation-strengthened [16, 23, 24]. It also confirmed the rationality and feasibility of the novel surface modified method proposed in this research.

Fig. 3 shows the $\mathrm{X}$-ray diffractograms of the TGN sample nitrided at $530^{\circ} \mathrm{C}$ using nitriding potential of 2.80 for $11 \mathrm{~h}$, the CGN sample treated using nitriding potential of 0.30 for $15 \mathrm{~h}$, and the USPed CGN sample. The surface layer in the TGN sample contained strong diffraction peaks of $\varepsilon-\mathrm{Fe}_{2-3} \mathrm{~N}$ and $\gamma^{\prime}-\mathrm{Fe}_{4} \mathrm{~N}$ phases, whereas that of the CGN sample consisted of entirely $\alpha-(\mathrm{Fe}, \mathrm{N})$ phases. Except for traces of diffraction peak broadening, no new diffraction peaks had been observed in the X-ray diffractogram of the USPed sample. TEM observations showed that the CL (Fig. 4a) on the top surface of the TGN sample was composed of nitride grains of submicrometer sizes (Fig. 4b). It is worth noting that the peened compound-free nitrided layer was subdivided into three zones with different colors after etching, as marked in Fig. 4c. A dark-field TEM image, as shown in Fig. 4d, verified that the severely deformed outermost layer (Zone I) was composed of ultra-fine grains $(100 \sim 200 \mathrm{~nm})$ in majority and a few amount of nano-crystalline grains $(20 \sim 80 \mathrm{~nm})$, as indicated by the selected area electron diffractogram inset. Beneath the top surface layer (Zone II), lamellar structures with an average width of approximately $180 \mathrm{~nm}$ were identified from Fig. 4e, indicating the formation of the elongated and fine grains. The observation of grain refinement and 
formation of lamellar structures induced by USP is accordance with the previous reports in both ferritic and martensitic steels [25, 26]. Lastly, a common nitrogen diffusion layer covered Zone III.

\subsection{Surface hardness and toughness}

The hardness-depth profiles of the nitrided and combined treated cases are presented in Fig. 5. Both surface hardness and cross-sectional hardness distribution of the TGN sample were higher than those of the CGN sample, which were attributed to the formation of compound layer [5-7]. The hardness distribution rule clearly showed that each treated layer had a similar effective case depth. It is noted that the hardness in the region quite close to the surface of the CGN sample was increased after subsequent USP treatment. The increase of surface hardness after USP is mostly attributed to the grain refinement and plastic deformation of martensitic matrix, according to the similar harden mechanism in shot peened martensitic steel [25]. Fig. 6 shows the in-depth residual stress distributions of the surface-hardened samples. Both nitriding and USP could induce compressive residual stress and the combined process of CGN and USP had generated deeper compressive residual stress profile with higher values with the maximum of $847 \mathrm{MPa}$. In particular, the combined process introduced a compressive stress of maximum magnitude at a distance of $100 \mu \mathrm{m}$ from the surface, implying that many defects are existing in region near the surface [15]. It is reasonable to conclude that the enhanced compressive residual stress and the unique distribution would be beneficial to the fatigue performance $[16,27]$.

Figs. 7a-d show the microstructure observation of the indentation in each sample. It was clearly proven that there existed an inverse relationship between hardness and toughness in a single gas nitriding process. Typical "Palmqvist-type" cracks could be observed on the surface of the TGN sample at loads ranging from 1 to $30 \mathrm{~kg}$, indicating an inherent brittleness and low bearing capacity of CL, whereas no obvious crack appeared in CGN and USPed samples at a load of $30 \mathrm{~kg}$. Fracture toughness $\left(K_{\mathrm{Ic} 0}\right)$ of the CL was approximately 5.15 $\mathrm{MPa} \mathrm{m}^{1 / 2}$ (Fig. 7e), which was calculated using the Palmqvist crack mode $[23,24]$. The absence of cracks and the relatively short diagonal 
length shown in the micro-indentation of the USPed sample revealed that the surface hardness was further improved after USP without sacrificing toughness. The excellent combination of surface hardness and toughness would be beneficial to wear resistance, especially under heavy load conditions [20].

\subsection{Wear characteristics}

Fig. 8 illustrates the variations of wear weight loss with the normal loads ranging from 49 to $392 \mathrm{~N}$, together with the corresponding wear-enhanced extent of differently

treated samples that was calculated by $\frac{w_{s}-w_{0}}{w_{0}} \times 100 \%\left(w_{s}\right.$ and $w_{0}$ are the wear weight losses of the surface modified samples and untreated samples, respectively). There existed distinct features of wear characteristics as reflected by the competition of weight loss under different load ranges among the three treated samples. The weight loss model was broadly divided into three regions (see Fig. 8). (A) The TGN sample showed a minimum weight loss under wear loads ranging from 49 to $147 \mathrm{~N}$, indicating the best wear resistance. (B) At the load range of 196 294 N, the USPed CGN sample presented the least wear loss, and the compound-free nitrided layer showed higher wear resistance than the compound layer; (C) With further increments of wear load from 294 to $392 \mathrm{~N}$, the combined process took an absolutely advantage in enhancing wear resistance. However, the wear loss of the compound-free nitrided layer became higher than that of the compound layer, indicating a degraded wear property. In order to explain the wear mechanisms and to investigate the effect of the surface treatment on the wear response of each type of nitrided layer, a selection of microstructures of the worn surface were observed and illustrated in Fig. 9.

Region A Similar to what was observed on other worn surfaces of nitrided alloys at slight loads, adhesive wear is the dominant wear mechanism [9]. The formation of the CL with relatively high surface hardness was particularly effective in resisting wear under the load range which would not break the surface. Also note that, for the USPed sample, higher surface hardness had not induced better wear resistance, as shown in the forefront of the model. We concluded that this contrary relationship between hardness and wear resistance was strongly influenced by the rough surface of the USPed sample 
(as shown in Fig. 7d), causing drastic wear in the initial stage of sliding.

Region B As shown in inset images of Fig. 9, both density and depth of the wear track were increased with an increase in the normal load for all treated samples, indicating wear aggravation. Obvious traces of surface spalling (CL removal) could be observed on the worn surface of the TGN sample with increasing the wear load up to 196 N (Fig. 9a). Such a phenomenon of CL spalling was not, in the least, infrequent either in previous theoretical research or in actual service of the nitrided components [9-11]. It is demonstrated that the hard abrasive particles formed by the spalling CL will stay in the contact zone, whereby inducing abrasive wear with accelerated weight loss. This would explain the poor wear property of the TGN sample at a load range from 196 to $294 \mathrm{~N}$. It is clear that the formation of the compound-free nitrided layer was effective in avoiding surface brittle flaking off and the subsequent abrasive wear, as observed in Fig. 9b. Although with a similar wear mechanism (Fig. 9b and 9c), the USPed CGN sample showed more excellent wear resistance than the CGN sample at this load range, owing to the further enhancement of surface hardness via USP treatment.

Region C The surface morphologies of the three treated samples after a wear test with a load of $392 \mathrm{~N}$ are shown in Figs. 9d-f. The worn surface layers as characterized by severe damage indicated that heavier loads could cause severe wear. The formation of large flakes on the worn surface of the CGN sample (Fig. 9e) caused a direct result of accelerated weight loss. In order to further clarify the wear mechanism of each type of surface layer under heavy loads, microstructure observation of cross-sectional of the samples following a wear test at a load of $392 \mathrm{~N}$ were carried out (Figs. 9g-i). With the accelerated removal of the surface layer during wear, the new surface layer presented a relatively lower hardness. As a result, the benefits of hardness distribution of TGN and USP samples stood out. Large wear debris was observed in the cross-section of the CGN sample, which had the lowest hardness distribution. Moreover, the appearance of elongated microstructures implied that plastic deformation was induced during sliding under heavy load range. The present worn characterization proved the conclusions from Kato [28] that the severe wear under heavy loads was characterized by plastic 
deformation, metal transfer to the disc surface, "white-etched" layer formation, and the production of large metallic $(\mathrm{Fe})$ wear debris.

Generation of subsurface microcracks with a small angle to the contact surface of the wear sample suggested the existence of large subsurface shear stress during heavy load wear and showed a typical feature of contact fatigue $[3,4]$. The vibration of the contact interface, the uneven distribution of wear debris, as well as the oxidation might develop a lot of micro-contacts on the contact surface under heavy load range. This situation generates locally very high contact pressure, resulting in very higher values of the peak shear stresses. To those high stresses caused by local external loads, must be superimposed the residual stress induced by surface treatments applied. The higher residual compressive stresses can produce a decrease in total amount of stress (sum of the residual and the external load ones), and the unique distribution of compressive state of stress inhibit an initiated crack to propagate $[3,15,16]$. Moreover, a higher load bearing capacity could be achieved for the hardened case with a deformed diffusion layer, which could eliminate the danger of stress concentration at the layer-core interface [27]. The significantly enhanced compressive stress and lots of defects existing in subsurface strongly prevented the development of the cracks in cross-section of the USPed sample (Fig. 9i).

In this research, it is clearly showed that the pin-on-disc wear under heavy loads involves not only the surface scuffing, but also contact fatigue behavior. In addition to the compressive residual stress, USP treatment also introduced a worsening of the surface roughness, which will reduce the scratch resistance and facilitate crack initiation under fatigue loading [29, 30]. Despite this, the severely deformed compound-free nitrided layer presented desirable wear resistance especially under heavy loads and the most important characteristic of the layer is the comprehensive performance supporting by the high hardness, toughness and the significantly enhanced residual compressive stress. In view of the roughness of the peened surface can be controlled in practical [30], this can also be considered a case in which combined gas nitriding can be used in place of carburizing, as regard to a low carbon steel. The wear characteristics of AISI 4140 
steel under the selected extremely high wear speed and heavy load can provide technical references for the design of surface strengthening for gears used in high-speed and heavy-duty applications.

\section{Conclusion}

In summary, the wear resistance of AISI 4140 steel, especially under heavy loads, can be enhanced by controlled gas nitriding combined with ultrasonic shot peening. A strong and tough surface gradient structure, where an ultra-fine-crystalline layer exists in the surface layer and a deformed nitrogen diffusion zone is beneath, can be obtained. The integrative functions of high hardness, toughness and the significantly enhanced residual compressive stress can inhibit surface brittle fracture and suppress subsurface crack development during wear at heavy loads. The present two-step surface treatment provides an effective approach to enhancing the wear resistance of gears used in high-speed and heavy-duty applications.

\section{Acknowledgments}

Bo Wang gratefully acknowledges the financial support from the National Natural Science Foundation of China (Grant No. 51701122) and H.C. Ørsted fellowship co-funded by Marie-Curie Actions. Q. Wang, Shanghai University, is acknowledged for help with the ultrasonic shot peening treatments.

\section{References}

[1] A. Kahraman, H. Ding, Wear in Gears, in: Q.J. Wang, Y.-W. Chung (Eds.), Encycl. Tribol., Springer US, Boston, MA, 2013: pp. 3993-4001.

[2] S.J. Bull, J.T. Evans, B.A. Shaw, D.A. Hofmann, The effect of the white layer on micro-pitting and surface contact fatigue failure of nitrided gears, Proc. Inst. Mech. Eng. 213(1999), 305-313.

[3] M. Boniardi, F.D. Errico, C. Tagliabue, Influence of carburizing and nitriding on failure of gears-A case study, Eng. Fail. Anal. 13(2006), 312-339. 
[4] C. Santus, M. Beghini, I. Bartilotta, M. Facchini, Surface and subsurface rolling contact fatigue characteristic depths and proposal of stress indexes, Int. J. Fatigue 45 (2012): 71-81.

[5] T. Bell, Source book on nitriding, ASM, Met. Park. OH. 1977, pp. 266-278.

[6] E.J. Mittemeijer, M.A.J. Somers, eds. Thermochemical Surface Engineering of Steels: Improving Materials Performance, Elsevier, 2014, pp. 3-5.

[7] M.A.J. Somers, E.J. Mittemeijer, Layer-growth kinetics on gaseous nitriding of pure iron: evaluation of diffusion coefficients for nitrogen in iron nitrides, Metall. Mate. Trans. A 26 (1995) 57-74.

[8] S. Jegou, L. Barrallier, G. Fallot, Gaseous nitriding behaviour of 33CrMoV12-9 steel: Evolution of the grain boundaries precipitation and influence on residual stress, Surf. Coat. Tech. 339 (2018): 78-90.

[9] G. Castro, A. Fernández-Vicente, J. Cid, Influence of the nitriding time in the wear behaviour of an AISI H13 steel during a crankshaft forging process, Wear 263 (2007) 1375-1385.

[10]D. Panfil, M. Kulka, P. Wach, J. Michalski, D. Przestacki, Nanomechanical properties of iron nitrides produced on $42 \mathrm{CrMo} 4$ steel by controlled gas nitriding and laser heat treatment, J. Alloys Comp. 706 (2017) 63-75.

[11]B. Wang, X. Zhao, W. Li, M. Qin, J. Gu, Effect of nitrided-layer microstructure control on wear behavior of AISI H13 hot work die steel, Appl. Surf. Sci. 431 (2018) $39-43$.

[12]W.P. Tong, N.R. Tao, Z.B. Wang, J. Lu, K. Lu, Nitriding iron at lower temperatures, Science 299 (2003) 686-688.

[13]W.P. Tong, N.R. Tao, Z.B. Wang, H.W. Zhang, J. Lu, K. Lu, The formation of $\varepsilon-\mathrm{Fe}_{3}-$ ${ }_{2} \mathrm{~N}$ phase in a nanocrystalline Fe, Scr. Mater. 50 (2004) 647-650.

[14]W.P. Tong, C.Z. Liu, W. Wang, N.R. Tao, Z.B. Wang, L. Zuo, J.C. He, Gaseous nitriding of iron with a nanostructured surface layer, Scri. Mater. 57 (2007) 533-536.

[15]J. Sun, W.P. Tong, H. Zhang, L. Zuo, Z.B. Wang, Evaluation of surface-modified 
20CrMo by plasma nitriding coupled with ion sputtering and SMAT, Surf. Coat. Tech. 213 (2012): 247-252.

[16]S.M. Hassani-Gangaraj, A. Moridi, M. Guagliano, A. Ghidini, M. Boniardi, The effect of nitriding, severe shot peening and their combination on the fatigue behavior and micro-structure of a low-alloy steel, Int. J. Fatigue 62 (2014) 67-76.

[17]M.A. Terres, A. Mohamed, L. Nabil, and S. Habib, Effect of nitriding and shot-peening on the fatigue behavior of $42 \mathrm{CrMo} 4$ steel: Experimental analysis and predictive approach, Mater. Des. 35 (2012): 741-748.

[18]A.C. Batista, A.M. Dias, J.L. Lebrun, J.C. Le Flour, G. Inglebert, Contact fatigue of automotive gears: evolution and effects of residual stresses introduced by surface treatments, Fatigue Fract. Eng. M. 23 (2000): 217-228.

[19]Y.K. Gao, Influence of deep-nitriding and shot peening on rolling contact fatigue performance of 32Cr3MoVA steel, J. Mater. Eng. Perform. 17 (2008): 455-459.

[20]B. Wang, Z.Q. Lv, Z.A. Zhou, S.H. Sun, X. Huang, W.T. Fu, Combined effect of rapid nitriding and plastic deformation on the surface strength, toughness and wear resistance of steel 38CrMoAlA, In IOP Conference Series: Mater. Sci. Eng. Vol. 89. No. 1. IOP Publishing, 2015.

[21]M. Yang, R.D. Sisson, Gaseous nitriding process control: application of customised lehrer diagrams, Int. Heat Treat. Surf. Eng. 7 (2013): 164-171.

[22]S. Bagherifard, M. Guagliano, Fatigue behavior of a low-alloy steel with nanostructured surface obtained by severe shot peening, Eng. Fract. Mech. 81 (2012): 56-68.

[23]C. Kwietniewski, W. Fontana, C. Moraes, A. da, S. Rocha, T. Hirsch, A. Regaly, Nitrided layer embrittlement due to edge effect on duplex treated AISI M2 high-speed steel Surf. Coat. Technol. 179 (2004): 27-32.

[24]D. Nlan, V. Leskovsek, M. Jenko, Estimation of fracture toughness of nitride compound layers on tool steel by application of the Vickers indentation method, Surf. Coat. Tech. 201 (2006): 182-188.

[25]R. Yang, X. Zhang, D. Mallipeddi, N. Angelou, H.L. Toftegaard, Y. Li, J. Ahlström, 
L. Lorentzen, G. Wu, and X. Huang, Effect of shot peening on the residual stress and mechanical behaviour of low-temperature and high-temperature annealed martensitic gear steel 18CrNiMo7-6, IOP Conference Series: Mater. Sci. Eng. 219 (2017) 1-7.

[26]X. Zhang, N. Hansen, Y. Gao, X. Huang, Hall-Petch and dislocation strengthening in graded nanostructured steel, Acta Mater.16 (2012): 5933-5943.

[27]Y. Lin, J. Lu, L. Wang, T. Xu, Q. Xue, Surface nanocrystallization by surface mechanical attrition treatment and its effect on structure and properties of plasma nitrided AISI 321 stainless steel, Acta Mater. 54 (2006): 5599-5605.

[28]H. Kato, T.S. Eyre, B. Ralph, Wear mechanism map of nitrided steel, Acta Metall. Mater. 42 (1994): 1703-1713.

[29]A.L. Wen, R.M. Ren, S. Wang, J.Y. Yang, Effect of surface nanocrystallization method on fatigue strength of TA2, Mater. Sci. Forum 620 (2009): 545-549.

[30]S. Bagherifard, R. Ghelichi, M. Guagliano, Numerical and experimental analysis of surface roughness generated by shot peening. App. Surf. Sci. 258 (2012): $6831-6840$ 


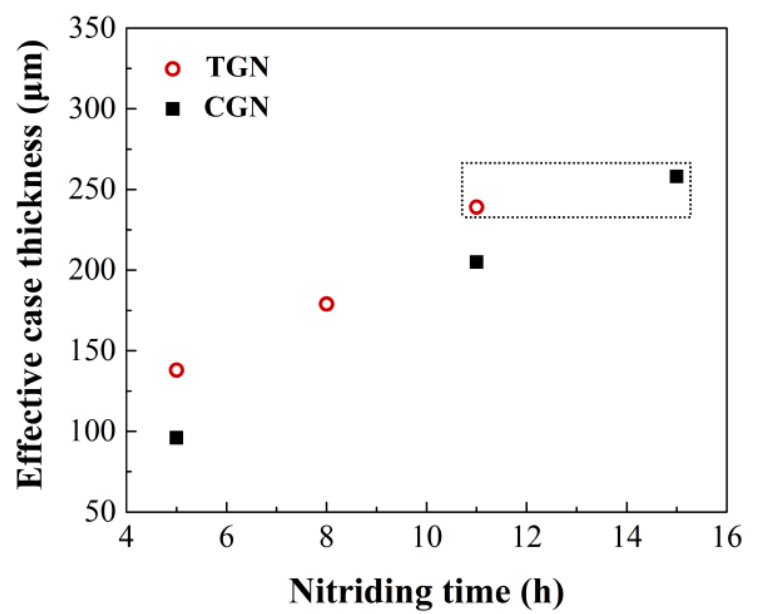

Fig. 1. Surface phase composition and effective case thickness of the nitrided layers treated under different nitriding parameters.
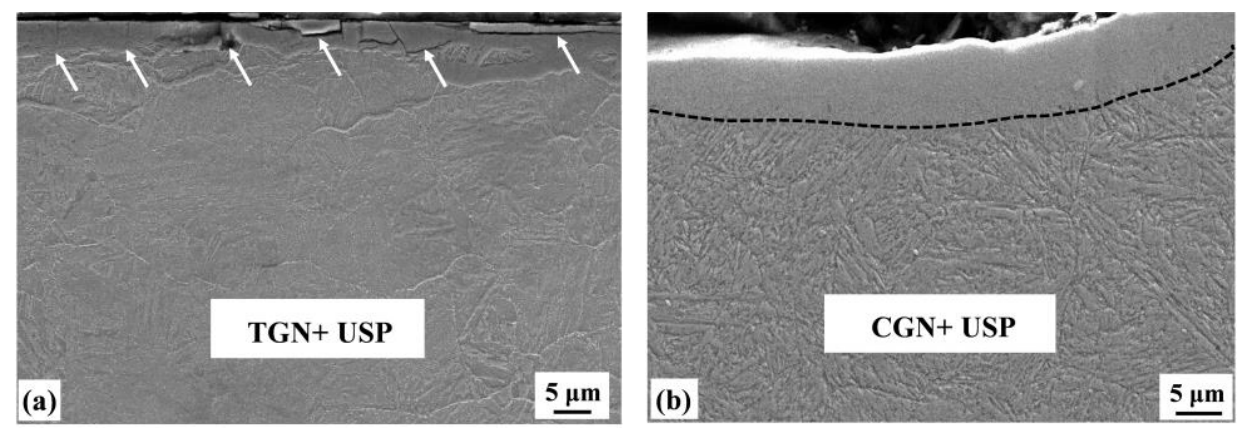

Fig. 2. Cross-sectional observations of samples treated by (a) TGN+USP and (b) CGN+USP.

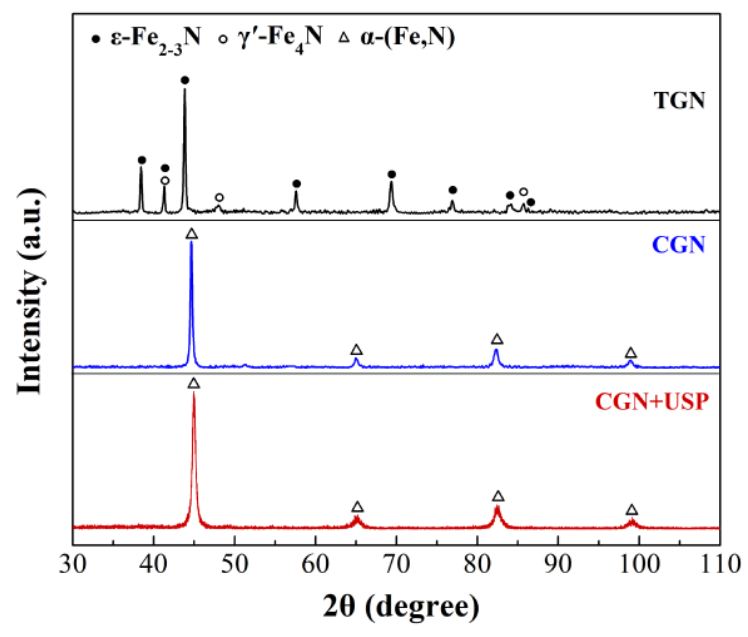

Fig. 3. X-ray diffractograms showing the phase structure of the three treated samples. 


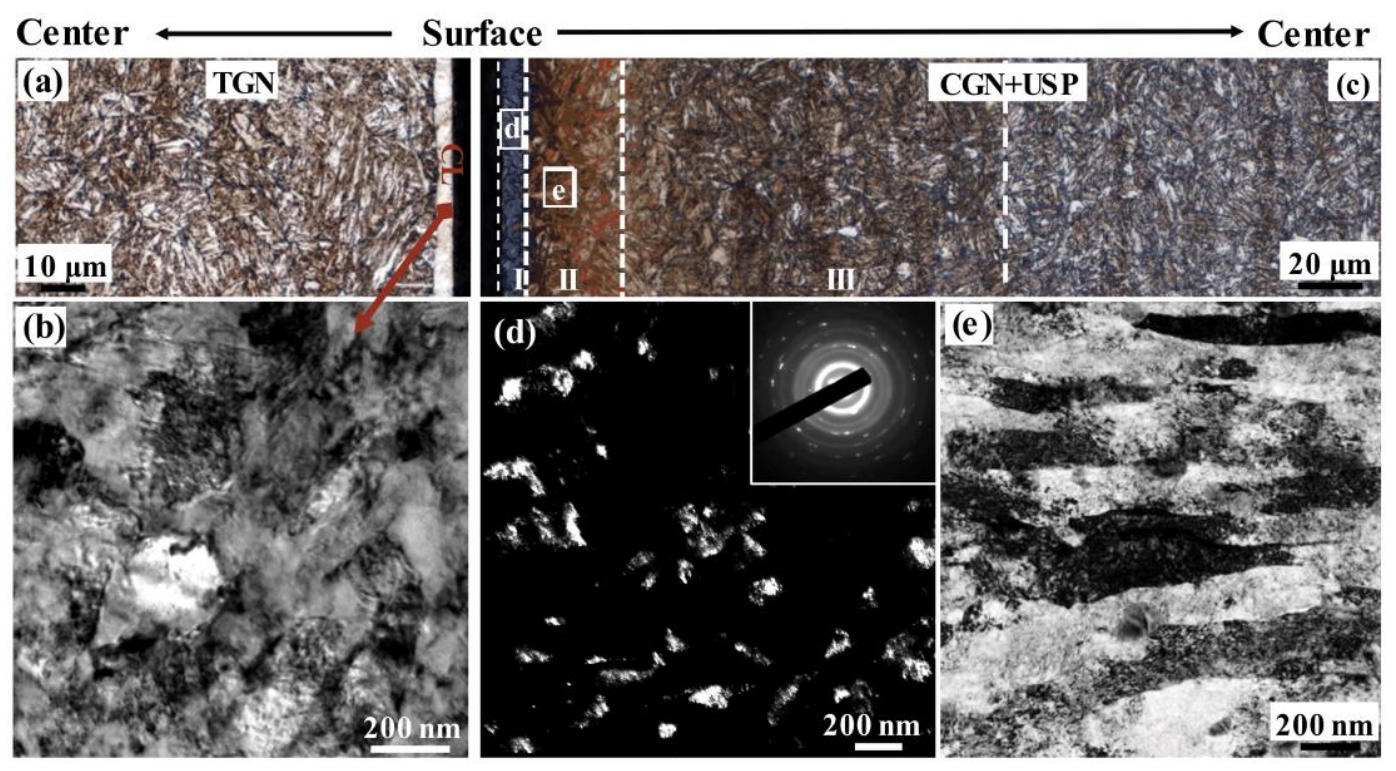

Fig. 4. Cross-sectional optical micrographic of TGN sample (a) and a bright-field TEM image of the CL (b). Cross-sectional OM observation of the USPed sample (c), and dark-field (d) and bright-field TEM images (e) showing microstructures in top and subsurface layer, respectively. Inset in (d) is the corresponding selected area electron diffractogram.

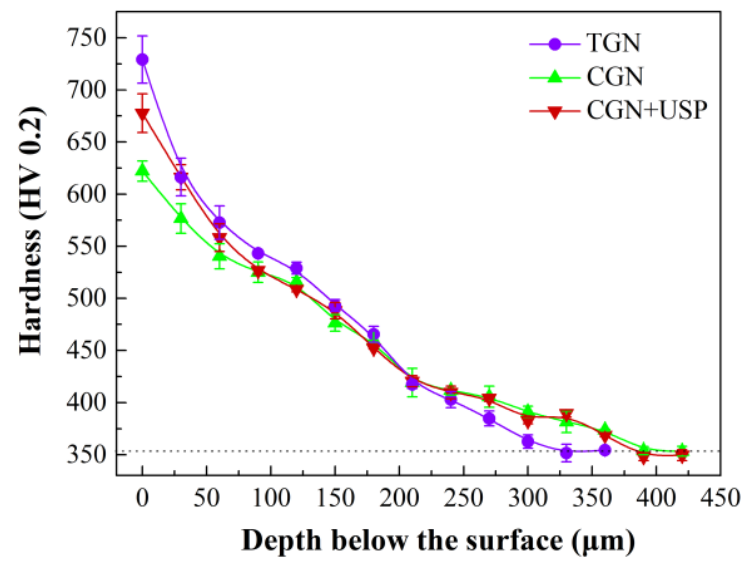

Fig. 5. Hardness-depth profiles of the nitrided and combined treated samples. 


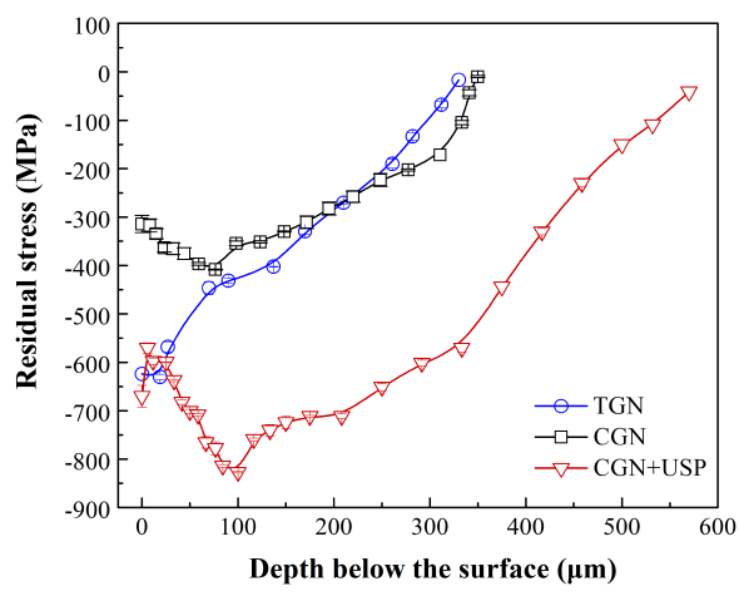

Fig. 6. Variations in the residual stress along depth from the top surface layer for nitrided and combined treated sample.
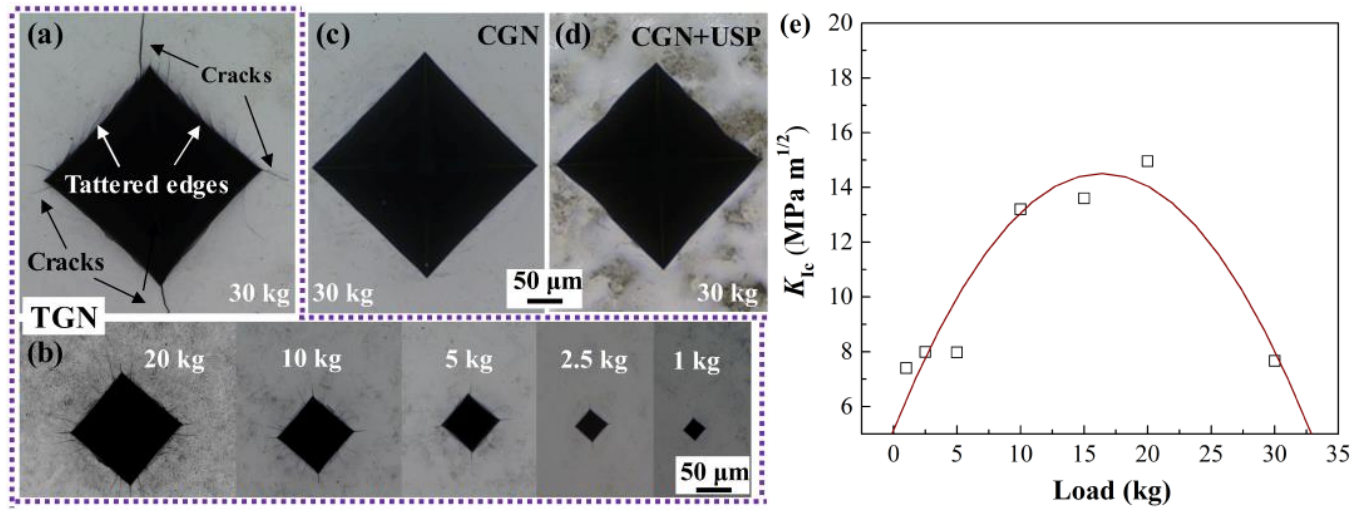

Fig. 7. Optical micrographs of surface indentations for TGN samples at loads ranging

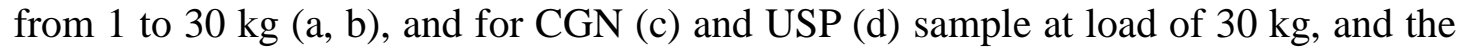
calculated $K_{\text {Ic }}$ values (e). 


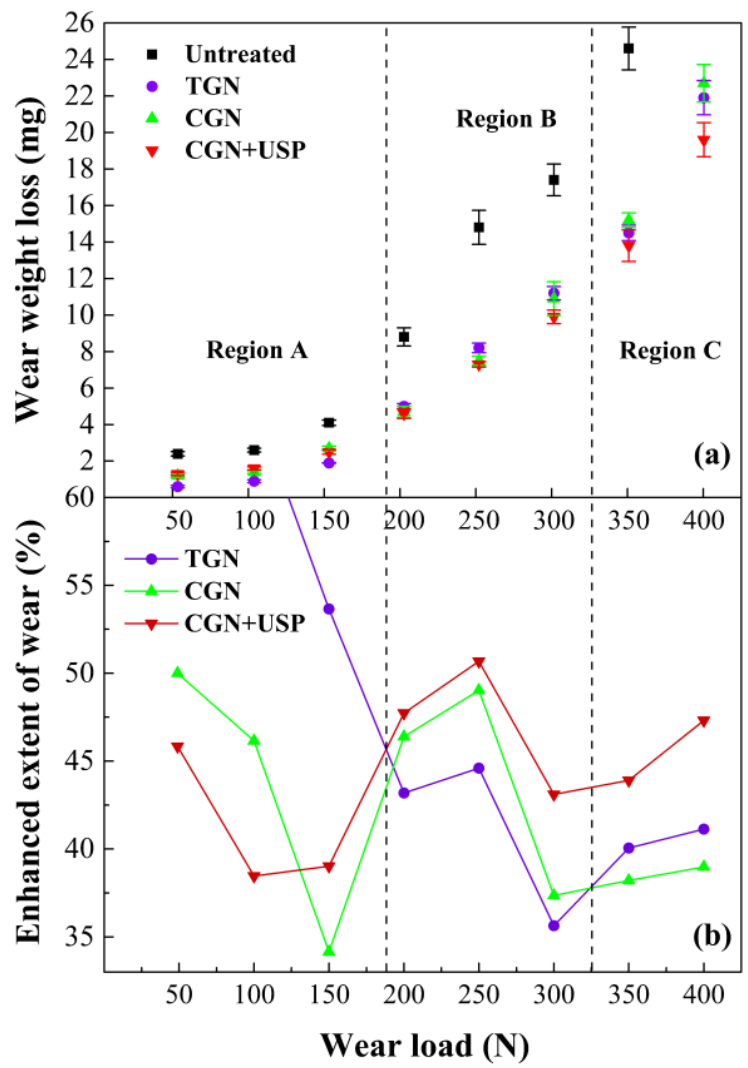

Fig. 8. Wear weight loss (a) and the wear-enhanced extent (b) at various loads ranging from 49 to $392 \mathrm{~N}$ for the TGN samples, and the CGN samples before and after USP. 

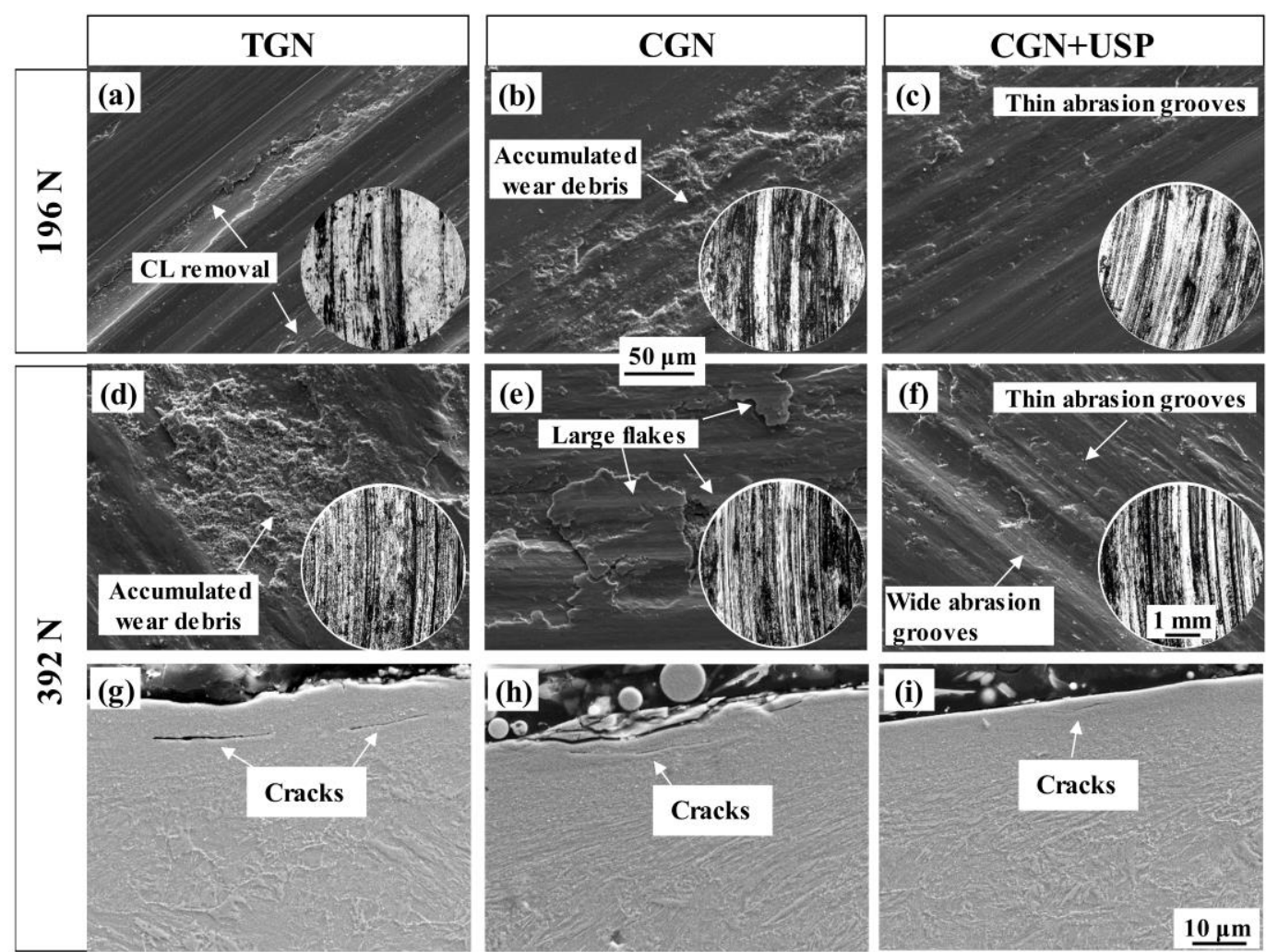

Fig. 9. Surface morphologies of wear scars for TGN, CGN and USP samples under loads of $196 \mathrm{~N}(\mathrm{a}-\mathrm{c})$ and $392 \mathrm{~N}(\mathrm{~d}-\mathrm{f})$, and cross-sectional microstructure of each worn sample at $392 \mathrm{~N}$ (g-i). Insets show the corresponding macro wear morphologies. 